\title{
Valorização do Pescado a Partir da Preparação de Novos Produtos
}

\author{
MARIA LEONOR NUNES*
}

Nos últimos anos a procura de pescado e produtos derivados tem aumentado na maioria dos paises, observando-se um interesse crescente por produtos mais elaborados e prontos a consumir. Neste sentido, tem-se procurado aproveitar melhor as espécies tradicionalmente exploradas e valorizar outras consideradas subaproveitadas.

Paralelamente têm vindo a ser melhoradas as tecnologias tradicionais de processamento e introduzidos novos equipamentos e tecnologias de conservação, processamento $\mathrm{e}$ embalagem. Entre as novas tecnologias de processamento destaca-se a preparação de polpas de pescado e de surimi que constituem importantes matérias primas para a confecção de uma vasta gama de produtos alimentares.

Dada a actual importância económica da produção destes produtos destaca-se neste trabalho as metodologias mais recentes de preparação bem como 0 aproveitamento dos subprodutos.

\section{INTRODUCÃ̃O}

Nos últimos anos teve lugar uma evolução tecnológica profunda a nível da construção naval, dos equipamentos de captura e detecção bem como das estruturas de conservação e processamento do pescado, quer a bordo quer em terra, que conduziram a que os desembarques de pescado efectuados pela frota mundial triplicassem entre 1950 e 1970 . Na década de 80 houve uma estabilização das capturas, tendo estas, segundo as estimativas da FAO, se situado no início da década de noventa ao redor de 90 milhões de toneladas.

A par do referido aumento das capturas mundiais de pescado assiste-se a um decréscimo significativo da biomassa capturável devido ao tempo insuficiente para a recuperação dos recursos marinhos facto este que exige a aplicação de medidas de gestão e conservação mais rigorosas.
Face a estas limitações a indústria transformadora de pescado tem tido necessidade de estabelecer novas estratégias com 0 objectivo de racionalizar a utilização dos recursos pesqueiros, através de um correcto aproveitamento das espécies subaproveitadas e da diminuiçâo das perdas por rejeição ou por inadequado processamento, e de se adaptar melhor às exigências dos actuais mercados e consumidores.

De entre os processos tecnológi$\cos$ que melhor se ajustam a esta nova atitude destaca-se a preparação de polpas de pescado e surimi pelo facto destas tecnologias possibilitarem 0 aproveitamento de espécies menos interessantes para o consumo directo ou para serem processadas tradicionalmente bem como 0 aproveitamento dos subprodutos e restos.

\section{POLPAS DE PESCADO}

A produção de polpas, carne fragmentada sem pele e espinhas, é feita a partir de peixe previamente descabeçado e eviscerado, recorrendo a separadores mecânicos, equipamento este desenvolvido sobretudo na década de 60 no Japão e nos Estados Unidos.

As polpas de pescado apresentam características próprias conforme a espécie e a sua qualidade intrínseca, 0 tipo de manuseamento e o modo de preparação. Assim, regra geral, são mais escuras do que os filetes provenientes da mesma espécie, devido à incorporação de pequenos pedaços e pigmentos de pele e de algumas substâncias da medula, particularmente ricas em enzimas susceptíveis de catalizar reacções de escurecimento também facilitadas pelo maior contacto com o oxigénio do ar (BABBITT, 1986).

0 manuseamento e a conservação do pescado quer a bordo quer em terra têm de ser cuidados pois as enzimas e bactérias bem como os compostos de degradação são facilmente incorporados na massa muscular, podendo dar lugar a alterações significativas nas propriedades funcionais.
A textura, suculência, cor e 0 aroma das polpas podem ser melhoradas através da optimização das condiçōes de preparação para cada espécie, da incorporação de aditivos ou da adição de ingredientes adequados.

Estes produtos são quase sempre matérias primas intermédias pelo que a sua estabilidade em congelado determina a qualidade do produto final (REGENSTEIN, 1986). Vários autores tem-se dedicado a estudar as alterações em congelado, sabendo-se hoje que estas se manifestam fundamentalmente por modificações na textura e na capacidade de retenção da água no caso de espécies magras, enquanto que nas polpas preparadas a partir de espécies gordas 0 aparecimento de sabores desagradáveis e 0 escurecimento da cor são os aspectos negativos mais notórios (Quadro 1).

Pelo facto de se tratar de um material moldável ao qual é fácil adicionar aditivos, ingredientes ou saborizantes, as polpas têm uma vasta gama de aplicações quer como matéria prima quer como principal ingrediente na confecção de produtos prontos a cozinhar ou précozinhados, sendo, no entanto, a principal utilização na preparação de surimi.

\section{SURIMI}

Este produto, cujo volume de produção atinge actualmente a nivel mundial mais de 500000 toneladas por ano, é constituido basicamente por proteínas miofibrilares estabilizadas com crioprotectores (Quadro 1). Em regra, não apresenta cheiro nem sabor, tem cor branca ou muito clara e boas características funcionais, em particular elevada capacidade gelificante.

As espécies mais utilizadas são as que se encontram disponiveis em maior quantidade e a um preço razoável e cujas proteinas apresentam boas propriedades gelificantes, destacando-se 0 escamudo do Alaska (Theragra chalcogramma), a pescada do Pacífico norte (Merluccius spp.), a pescada austral (Merluccius polylepis) e o verdinho austral 
QUADRO I. Caracterização sumária de polpas de pescado e surimi

\begin{tabular}{lcc}
\hline & Polpa & Surimi \\
\hline Proteinas Totais (\%) & $15-20^{*}$ & $12-17^{\star *}$ \\
$\quad$ Miofibrilares (\%) & $70-75$ & 100 \\
$\quad$ Sarcoplásmicas (\%) & $20-25$ & $\approx 0$ \\
$\quad$ Estroma (\%) & 3 & $\approx 0$ \\
Azoto não proteico (\%) & $0,5-1,5$ & $\approx 0$ \\
Líquidos (\%) & $0,5-30$ & $\approx 0$ \\
Açucares (\%) & $<1$ & 0,2 \\
Polifosfatos (\%) & $\approx 0$ & $75-80^{* *}$ \\
Água (\%) & $60-80^{*}$ & Boa estabilidade \\
Comportamento & Modificações profundas & \\
em congelado & nos lipidos e nas proteinas & \\
\hline
\end{tabular}

- Depende da espécie e da época do ano.

$*$ Depende do processo de fabrico

(Microme-sistius australis). No entanto, dada a progressiva diminuição dos stocks destas espécies e 0 sucesso que o surimi tem registado, começaram a ser também utilizadas espécies pelágicas, nomeadamente menhadem (Brevortia tyrannus), carapau (Trachurus trachurus), cavala (Scomber japonicus) e sardinha do Pacífico (Sardinops melanosticta), bem como de aquacultura entre as quais se salienta a tilápia (Tilapia spp.). Na Figura 1 indica-se a localização geográfica das espécies mais utilizadas nos últimos anos no fabrico de surimi
A qualidade intrínseca da espécie afecta as características do surimi, aliás como acontece com outros produtos, sendo de salientar que o pescado capturado durante e após a desova produz em regra surimi de qualidade inferior.

0 peixe destinado à preparação de surimi deve ser cuidadosamente manuseado e conservado a bordo a fim de evitar perdas de frescura que podem afectar de modo determinante a qualidade do

Fig. 1 - Localização geográfica de algumas das principais espécies utilizadas na preparação de surimi.

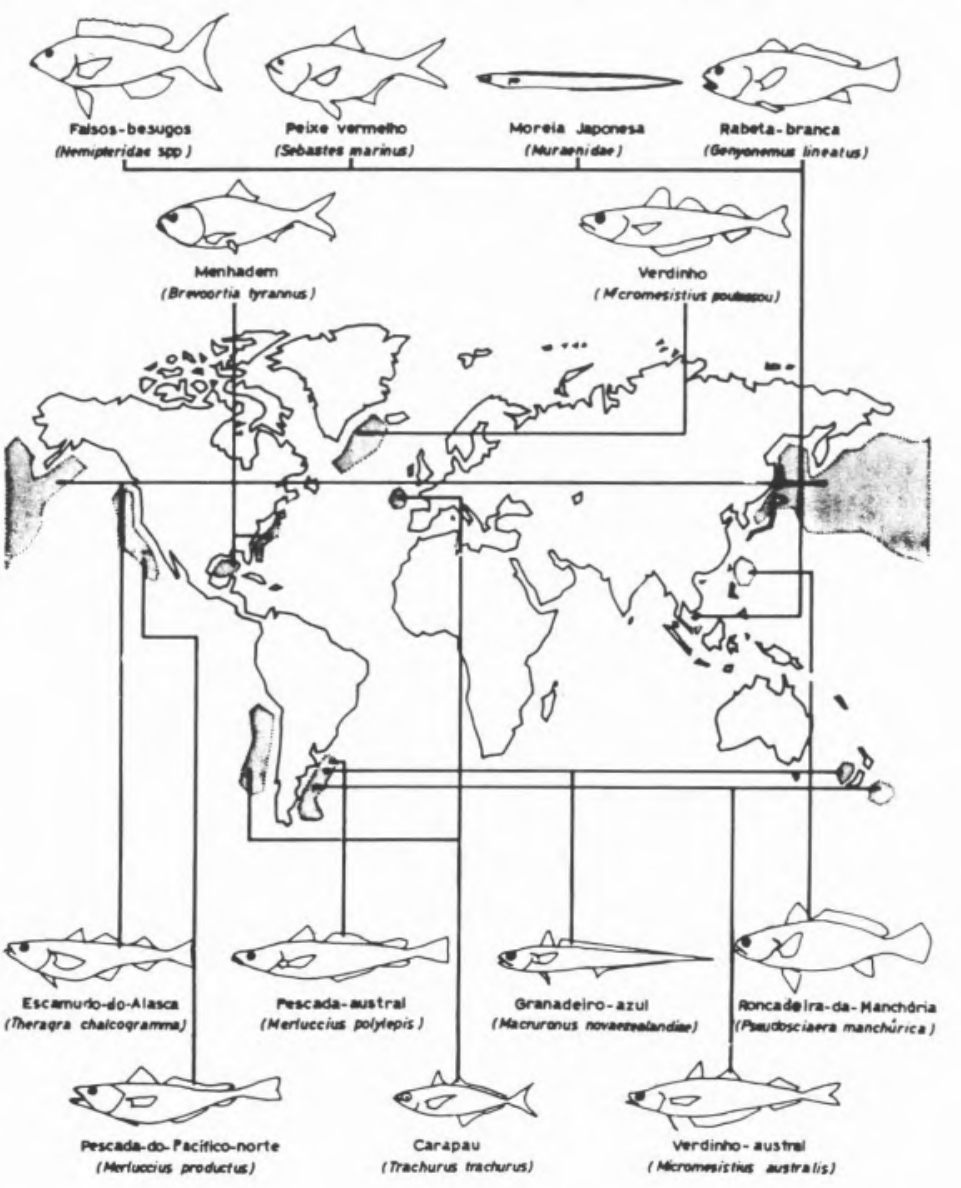

surimi. Assim, é conveniente conservá-lo desde a captura até ao processamento a temperaturas próximas dos $0^{\circ} \mathrm{C}$, recorrendo ao uso de gelo ou à água do mar refrigerada.

A lavagem do pescado após descabeçamento eviscerado é essencial no sentido de impedir a actividade proteolitica das enzimas digestivas, a qual poderá contribuir para diminuir a qualidade do produto final. No caso dos gadídeos é aconselhada a filetagem antes da separação mecânica com o objectivo de remover a espinha central junto da qual permanecem sempre vestígios de enzimas, em particular a responsável pela demetilação do óxido de trimetilamina que vai decompor 0 óxido de trimetilamina em dimetilamina e formaldeido, sendo este último composto considerado responsável pela desnaturação das proteínas durante a armazenagem em congelado.

Na produção do surimi consideram-se normalmente 3 fases: preparação da polpa, lavagem e refinação e, por último, a incorporação de crioprotectores e eventualmente outros aditivos, como se ilustra na Figura 2.

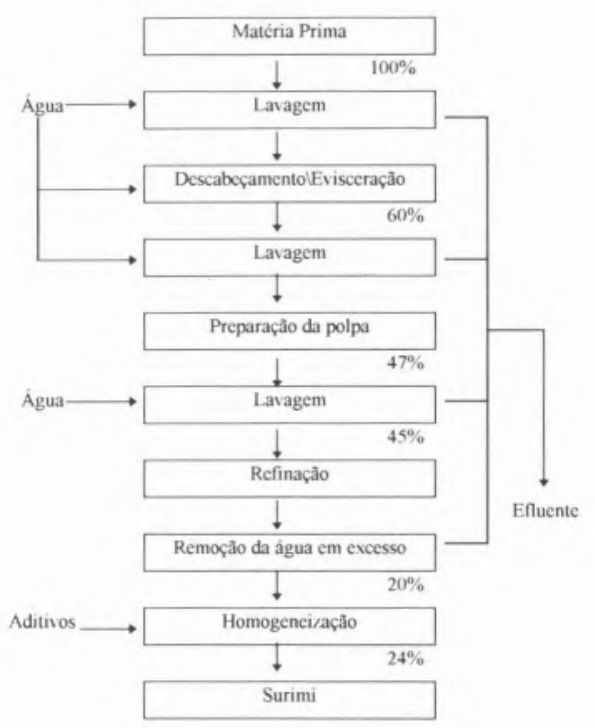

Fig. 2 - Diagrama geral de preparação de surimi.

As polpas obtidas por separação mecânica são lavadas duas a seis vezes, por períodos de 5 a 10 minutos, em água arrefecida, utilizando relações polpa/água entre 3 e 6 . Após cada lavagem intermédia a água em excesso é removida recorrendo a uma prensa e por último a uma centrífuga tipo decanter.

As características da água de lavagem são determinantes para a qualidade do produto final. Assim, a força iónica 
deve estar compreendida entre 0,005 e 0,1 e a presença de $\mathrm{Ca}^{2+} \mathrm{e} \mathrm{Mg}^{2+}$ em concentrações elevadas pode não só tornar a polpa mais sensivel a variações de temperatura como também contribuir para acelerar a desnaturação da actomiosina durante a armazenagem em congelado.

$0 \mathrm{pH}$ da água de lavagem, por seu lado, influencia a capacidade de ligação da água que por sua vez afecta as características de gelificação do produto final. Geralmente considera-se que valores próximos de 6,5 são os mais indicados para espécies magras e no caso das espécies gordas aconselha-se a utilização de bicarbonato de sódio $(0,2$ a papel segundo Suzuki \& Watabe (1986) é neutralizar $0 \mathrm{pH}$ intracelular e prevenir a sua descida durante a operação de lavagem. Quando $0 \mathrm{pH}$ desce a valores inferiores a 6,0 a capacidade de gelificação diminui acentuadamente pelo facto da actomiosina se desnaturar muito rapidamente durante a armazenagem em congelado. Frequentemante adiciona-se $\mathrm{NaCl}(0,15-0,25 \%$ w/v) na última lavagem com o objectivo de facilitar a remoção da água em excesso.

Recentemente têm sido propostos processos para as espécies gordas, baseados na utilização de ultrasons (TAKAl et al.,1984) e $\mathrm{CO}_{2}$ supercritico (LANIER, 1985; ENDO et al., 1989) com o objectivo de eliminar mais facilmente os lípidos e 0 cheiro durante a operação de lavagem, contudo a desnaturação torna-os para já impraticáveis. Com 0 mesmo propósito vários autores (KATOH et al., 1989; NONAKA et al., 1989 e NISHIOKA et al., 1990) propuseram no final da década de 80 a utilização de moinhos coloidais ou de homogeneizadores especiais para reduzir 0 tamanho da partícula das polpas e assim facilitar o processo de lavagem. 0 tamanho da partícula pode variar entre 1 e $100 \mathrm{~m}$, de acordo com o tipo de equipamento. É igualmente aconselhado que a polpa seja micronizada e lavada no sentido de reduzir a oxidação dos lípidos e facilitar a sua separaneste caso deve ser feita recorrendo a centrífugas tipo decanter, operando entre 400 e $2500 \mathrm{~g}$, que também facilitam a remoção dos lípidos (Fig. 3).

A terceira fase do processo, adição de crioprotectores e eventualmente outros aditivos e ingredientes, é efectua-

QUADRO II. Alguns dos compostos mais frequentes referenciados como crioprotectores

Açúcares: Sorbitol, glucose, galactose, lactose, sacarose, maltose e frutose Aminoácidos: Ácido aspártico, ácido glutâmico, cisteina e glutationa

Ácidos carboxilicos: Malónico, maleico, glutárico, láctico, tartárico, cítrico e $\alpha$-amino-butirico $0,3 \%$ ) na primeira lavagem cujo principal proteica que resulta de tais processos,

da logo após a lavagem e refinação da polpa com o objectivo de minimizar a desnaturação das proteínas miofibrilares durante a armazenagem em congelado $\mathrm{e}$ prevenir a oxidação dos lípidos. Como antioxidantes são frequentemente referenciados 0 butil-hidroxianisol e 0 butilhidroxitolueno bem como alguns tocoferois enquanto que os polifosfatos, hidratos de carbono, aminoácidos e ácidos carboxilicos são os crioprotectores mais aconselhados (Quadro 2). De entre estes, os mais vulgarmente utilizados são 0 sorbitol (4\%), a sacarose $(4 \%)$ e os polifosfatos de sódio $(0,15 \%)$. Estes últimos por si só não têm um efeito crioprotecor, contudo, o efeito daqueles açúcares é mais acentuado na sua presença. Por vezes evita-se a adição da sacarose pelo sabor que confere e por provocar 0 aparecimento de uma coloração acastanhada durante a armazenagem em congelado. Alguns autores sugerem que para a estabilização de surimi de espécies gordas é mais eficaz utilizar $3 \%$ de clara de ovo, $5 \%$ de sorbitol e $0,2 \%$ de polifosfatos de sódio (NISHIOKA et al., 1990).

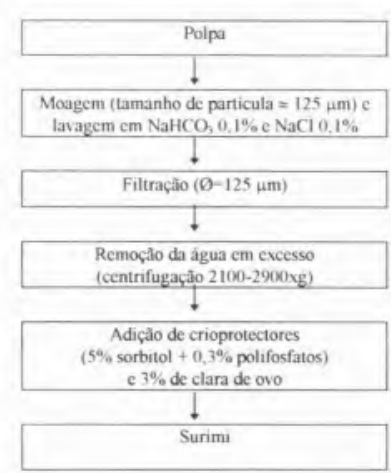

Fig. 3 - Diagramas de preparação

de surimi a partir de espécies gordas decorre das suas propriedades gelificantes. Assim, as proteínas miofibrilares do pescado têm uma maior capacidade de gelificação do que as das aves e mamíferos e por outro lado espécies de água
O principal interesse do surimi doce e de águas quentes têm geralmente capacidade de gelificação inferior às de águas frias.

$\mathrm{Na}$ formação destes geles as miofibrilas são dissociadas em actina F e miosina, a que se segue uma repolimerização. A solubilização é efectuada através da adição de sal ao surimi (2 a 3\%) e posterior homogeneização feita a vácuo a cerca de $4^{\circ} \mathrm{C}$ para evitar a desnaturação da actomiosina, pois se tal acontecer não haverá formação de gel. A presença de proteinas sarcoplásmicas ou lípidos bem como armazenagens deficientes no estado congelado podem também contribuir para a diminuição da capacidade de gelificação.

Os geles designados normalmente como "geles tipo Kamaboko" podem ser obtidos por aquecimento directo à temperatura de $90^{\circ} \mathrm{C}$ ou após "setting" a temperaturas inferiores a $40^{\circ} \mathrm{C} 0$ qual assegura a progressão entre a matriz sol-gel e a matriz proteica gelificada final. Normalmente o "setting" melhora a elasticidade porque facilita a reordenação das proteínas e o estabelecimento de interacções hidrofóbicas entre as cadeias

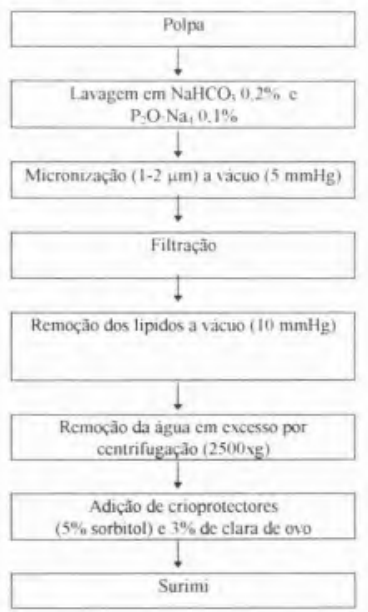

proteicas.

Frequentemente observa-se que no caso de espécies pelágicas o "setting" é uma fase importante porque caso contrário poderá ocorrer uma coagulação proteica que confere ao gel uma textura quebradiça. Ainda nestas espécies é também frequente 0 "modori", que consiste na destruição irreversivel da estru- 
tura do gel. Tem havido alguma especulação sobre a explicação deste fenómeno, assim, segundo alguns autores, é devido à presença de proteases alcalinas designadas como proteases indutoras do "modori" enquanto que segundo outros se deve a uma maior instabilidade das cadeias pesadas da miosina, instabilidade esta que é mais acentuada quando 0 "setting" tem lugar a temperaturas próximas de $60^{\circ} \mathrm{C}$ (KINOSHITA et al., 1990). Ainda de acordo com estes autores a adição de $3 \%$ de clara de ovo pode reduzir drasticamente a acção destas proteases. No sentido de alterar as caracteristicas do gel final é prática comum adicionar ingredientes na altura da sua preparação. Os amidos de diferentes origens, os carragenatos (em particular o iota), a clara de ovo e as proteínas de origem vegetal têm sido os mais referenciados.

\section{APROVEITAMENTO DE SLIPRODUTOS E RESTOS}

Nas diversas tecnologias de processamento de pescado e no processo de produção do surimi resultam diversos tipos de desperdícios. Estes são principalmente constítuidos por cabeças, vísceras, pele e espinhas resultantes das operações de descabeçamento, evisceração e preparação da polpa e por compostos solúveis na água e lípidos provenientes da lavagem e refinação da polpa.

Os primeiros, que podem atingir cerca de $40 \%$ do peso total do pescado, são normalmente encaminhados para a produção de farinha de peixe. No entanto, este material é já hoje utilizado em diversos paises para a extracção de biomoléculas, tais como enzimas e colagénio, e na preparação de concentrados proteicos. As enzimas podem ser utilizadas na indústria de lacticínios como substituto de coalho, na produção de produtos fermentados de pescado e peptonas, tendo estas últimas se revelado particularmente adequadas como meio de cultura de estirpes bacterianas com várias aplicações em biotecnologia. 0 colagénio, por seu lado, encontra aplicações quer na indústria alimentar quer em cosmética (GILDBERG et al., 1989 e GUERARD, 1978).

De entre os compostos solúveis na água de lavagem destacam-se as proteínas sarcoplásmicas cuja recuperação tem vindo a ser ensaiada por electrocoa-

QUADRO III. Recuperação e utilizações dos subprodutos da preparação do surimi

\begin{tabular}{lll}
\hline Moléculas & Fonte & Aplicações \\
\hline Lipoxigenase & Brânquias e pele & Potenciais aromatizantes \\
Leucina amino peptidase & Visceras & Fármacos \\
Colagenase e elastase & Visceras & Despelagem de lulas \\
Elastina e colagénio & Pele & Cosmética \\
$\begin{array}{c}\text { Péptidos e hidrolisados } \\
\text { proteicos }\end{array}$ & Visceras & Substitutos de péptidios, \\
$\begin{array}{c}\text { Pepsina, tripsina e quimotripsina } \\
\text { DNA, nucleósidos e hormonas }\end{array}$ & Visceras & Substratos para fermentação \\
organometálicas de crescimento & e músculo masculinas & Indústria de lactícinios \\
Insulina & Vármacos \\
\hline
\end{tabular}

gulação, precipitação e ultrafiltração a fim de permitir a reutilização das águas de lavagem e diminuir a carga poluente dos efluentes. A recuperação destas proteínas foi também estudada, recorrendo à reacção de plasteína com a qual se obtiveram rendimentos que rondavam os $67,5 \%$ da proteina solúvel (00SHIRO et al., 1981). Os produtos obtidos apresentam, em regra, razoável capacidade gelificante, um elevado teor proteico e boa disgestibilidade.

Os lípidos libertados durante a lavagem são outra importante fracção devido à sua composição em ácidos gordos polinsaturados de considerável valor terapêutico. A sua separação pode ser conseguida por centrifugação ou recorrendo a fluídos supercríticos ou quasecríticos. 0 interesse farmacológico e 0 elevado valor comercial destes produtos justifica a sua recuperação dado que pode contribuir para uma maior rentabilização do processo.

No quadro 3 apresenta-se um resumo dos produtos derivados que apresentam já potenciais aplicações industriais.

Convém, no entanto referir, que muitos dos compostos extraiveis têm utilizações muito limitadas devido aos altos custos de purificação, baixos rendimentos e uma influência notória das variações sazonais registadas nos recursos marinhos.

* Instituto Português de Investigação Maritima Av. de Brasilia, 1400 LISBOA

\section{REFERÊNCIAS}

J. K. Babbitt, Food Technol. 40 (1986) 97.

Y. Endo, K. Fujimoto, Bul. Jap. Soc. Sci. Fish. 36 (1989) 563
A. Gildberg, I. Batista, E. Strom, Biot. App. Biochem. 11 (1989) 413.

F. Guerard, Trav. Inst. Pêches Marit. 49 (1978) 199.

N. Katoh, A. Hashimoto, N. Nakagawa, K. Amano, Bul. Jap. Soc. Sci. Fish. 55 (1989) 507.

M. Kinoshita, H. Toyohara, Y. Shimizu, Proceedings of Chilling and Freezing of New Fish Products, TRS, 1990.

T. Lanier, Proceedings of the International Symposium on Seafood Including Surimi, 1985.

F. Nishioka, T. Tokumaga, S. Fujiwara, S. Yoshiora, Proceedings of Chilling and Freezing of New Fish Products, TRS, 1990.

M. Nonaka, F. Hirata, H. Saeki, Y. Sasamoto, Bul. Jap. Soc. Sci. Fish. 55 (1989) 1575.

Z. Ooshiro, M. Perez Won, S. Nakagawa, T. Itakura, S. Hayashi, Memoirs of Faculty of Fisheries Kagoshima University 30 (1981) 369.

J. M. Regenstein, Food Technol. 40 (1986) 101.

T. Suzuki, S. Watabe, Food Rev. Int. 2 (1986) 271.

R. Takai, H. Watanabe, S. Mizusawa, H. Hasegawa, Bul. Jap. Soc. Sci. Fish. 44 (1984) 1363. 